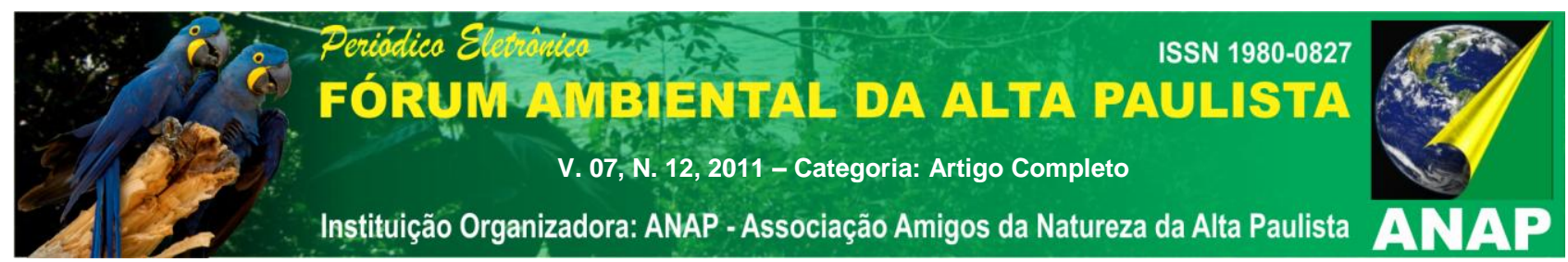

\title{
MÉTODO DE VALORAÇÃO DE CONTINGÊNCIA - DISPOSIÇÃO A PAGAR (DAP) PELO RECURSO “ÁGUA” NO MUNICÍPIO DE MERUOCA/CE.
}

Kaliny Kélvia Pessoa Siqueira Lima ${ }^{1}$

Fernando Daniel de Oliveira Mayorga ${ }^{2}$

RESUMO: A água é uma referência cultural e um bem social indispensável à adequada qualidade de vida da população. Este estudo tem por objetivos analisar o perfil sócio econômico dos usuários da água para medir a capacidade de pagamento pelo uso do recurso, fazer um levantamento das fontes de abastecimento (CAGECE, SAAE, rio, poço profundo, cacimbão, etc.) no município de Meruoca/CE, avaliar sob a ótica dos entrevistados a qualidade da água fornecida ao usuário, estimar um valor médio a água do município de Meruoca/CE, através da DAPM e um valor agregado ao recurso água. A pesquisa é quantiqualitativa, por método de valoração contingente que hipotetizando cenários distintos, no período de setembro do ano de 2010 a abril do ano de 2011, tendo amostra de 50 entrevistados. Utilizou-se como instrumento um questionário a fim de analisar resultados segundo a fórmula sugerida por Eutrirak \& Grandstaff. As DAPM's encontrados para os cenários A, B e C são, respectivamente, $R \$ 16,35 ; R \$ 13,17$ e $R \$ 15,63$ e, o valor agregado ao recurso água no município nos mesmos cenários foram, respectivamente, $R \$ 153.670,00, R \$ 80.264,00$ e $R \$ 107.188,00$. Conclui-se que fixar preço não deve ser visto unicamente como forma de equilibrar oferta e demanda, para Moraes (2009) ancorar o preço da água é essencial também como medida de assegurar o bem-estar social e manter o meio ambiente limpo.

Palavras-Chave: Valoração Contingente - Água - Meruoca/Ce.

\section{ESTRUTURA}

\subsection{INTRODUÇÃO}

\footnotetext{
${ }^{1}$ Autora. Graduada em Economia pela Universidade Federal do Ceará - UFC. Bolsista do Laboratório de Estudos Agrários e Desenvolvimento Sustentável.

2 Co-Autor. Doutorando em Estudos de Terras Áridas na Universidade do Arizona-EUA. Mestre em Economia Rural pela Universidade Federal do Ceará (2002), Graduado em Ciências Econômicas pela Universidade Federal do Ceará (1999). Professor assistente I da Universidade Federal do Ceará- Campus Sobral e, coordenador do Laboratório de Estudos Agrários e Desenvolvimento Sustentável
} 


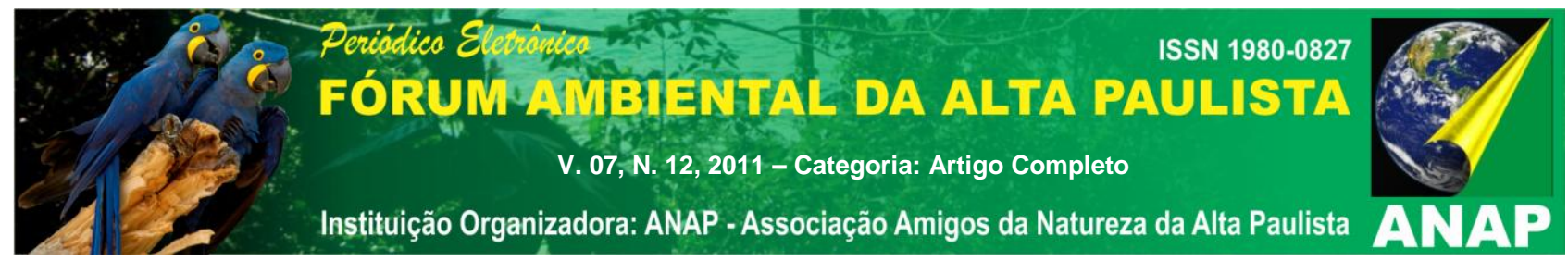

A dificuldade de água é o relevante problema pelo qual se mostra necessário o estudo proposto. Existe no município de Meruoca/CE agravantes na existência de água para abastecimento da população local. A partir disso, se faz necessário a introdução de uma metodologia que possa alocar recursos escassos de maneira a obter o maior benefício social.

Esta pesquisa tem como objetivo geral analisar a disposição a pagar (DAP) e a capacidade de pagamento pelo uso da água no município de Meruoca, no Estado do Ceará; e, como objetivos específicos, analisar o perfil socioeconômico dos usuários da água para medir a capacidade de pagamento pelo uso do recurso, fazer um levantamento das fontes de abastecimento (CAGECE, SAAE, rio, poço profundo, cacimbão, etc.), avaliar sob a ótica dos entrevistados a qualidade da água fornecida ao usuário, estimar um valor médio para água do município de Meruoca/CE, para cada cenário hipotético criado e apresentado a cada participante do estudo que faz uso do recurso "água", através da valoração de contingência de disposição a pagar (DAP), pelo uso da água de boa qualidade e segurança de abastecimento do recurso.

Caracteriza-se por uma pesquisa de caráter exploratório-descritivo, com abordagem quantitativa. Segundo Polit e Hungler (1995) esse tipo de estudo possibilita uma compreensão em profundidade do problema que se quer trabalhar a saber de seu cenário natural, sem impor um controle.

A pesquisa foi realizada com a comunidade que constitui o município de Meruoca CE, localizada no noroeste cearense, tendo como municípios limítrofes Massapé, Sobral e Alcântaras, possuindo uma área geográfica de 144,940km², cuja população 12.700 habitantes (IBGE, 2009). Apresenta como indicadores um Índice de Desenvolvimento Humano de 0,638 (PNUD, 2000); PIB de $\mathrm{R} \$ 20.037,00$ mil ao ano e seu PIB per capita é de $\mathrm{R} \$ 1.684,00$ (IBGE, 2005).

O estudo foi realizado no período de setembro do ano de 2010 a abril do ano de 2011, com fins de concluir os objetivos apresentados neste trabalho. Tendo por uma amostra de 25 entrevistados.

O Método utilizado para a realização deste estudo foi o de valoração de contingência que segundo May (2003), consiste na utilização de pesquisas amostrais para 


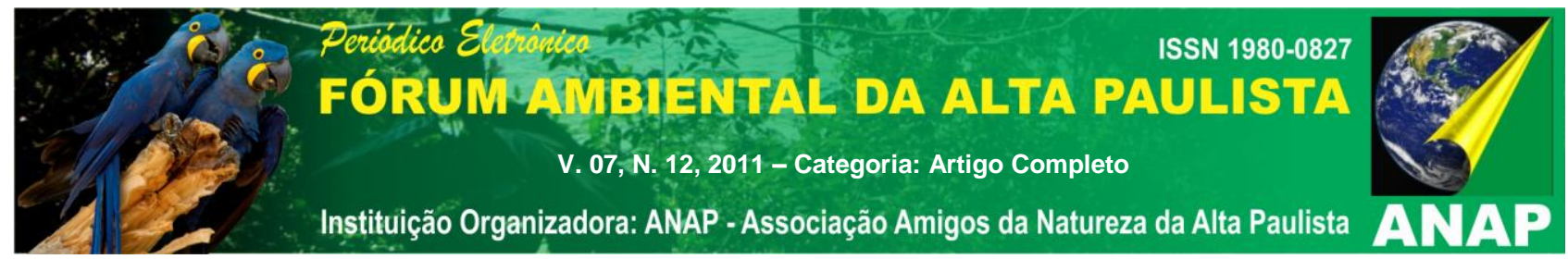

identificar, em termos monetários, as preferências individuais em relação a bens que não são comercializados em mercados.

As técnicas de valoração econômica ambiental buscam medir as preferências das pessoas por um recurso ou serviço ambiental e, portanto, o que está recebendo "valor" não é o meio ambiente ou o recurso ambiental, mas as preferências das pessoas em relação a mudanças de qualidade ou quantidade ofertada do recurso ambiental. Essas preferências individuais são traduzidas em medidas de bem-estar - variações compensatórias, excedente do consumidor e variação equivalente - que podem ser interpretadas como a disposição a pagar (DAP) de um indivíduo por uma melhoria ou incremento no recurso ambiental ou como a disposição a receber (DAR) uma piora ou decréscimo na oferta de recurso (MAY, 2003).

A aplicação desta metodologia foi dividida em três momentos. O primeiro consta de

uma avaliação sócio-econômica caracterizando o perfil dos participantes; o segundo, um reconhecimento quanto à disponibilidade de água para os usuários e, em terceiro, a formatação de três cenários hipotéticos propondo ao entrevistado a saber suas escolhas e preferências quanto a sua disposição a pagar pelo recurso "água”, os quais foram os seguintes (responderão somente as pessoas que possuem condição de pagar por algum valor ao recurso): Cenário $\mathrm{A}$ - Se existisse um abastecimento de água, implantado pelo governo, você estaria disposto a pagar pra ser beneficiado por esta água? Se sim, Quanto?; Cenário B - Se existisse um abastecimento de água implantado pelo governo, mas este não corresponde a sua necessidade, sendo falho quanto a disponibilidade de água diário, você estaria disposto a pagar para ter água? Se sim, quanto?; Cenário C Se o governo não implantasse um abastecimento de água para a população, você estaria disposto a pagar para ter água de um outro tipo de abastecimento, com poço ou cacimba? Se sim, quanto?

Os resultados foram analisados categoricamente sob a ótica das respostas contidas nos questionários respondidos. Com o intuito de dar maior credibilidade ao método de valoração contingente, estimou-se a disposição a pagar total (DAPT) e a disposição a pagar média (DAPM) a partir de técnica matemática. Os valores apanhados pelos entrevistados das DAP's foram estratificados de maneira ad-hoc ${ }^{3}$.

Neste estudo utilizou-se a técnica para calcular a disposição a pagar total (DAPT) pelo recurso água, tomando como a forma funcional de Eutrirak \& Gandstaff (apud Seroa

\footnotetext{
${ }^{3}$ Hipótese criada para estratificar os valores atribuídos pelos entrevistados dentro do valor mínimo e máximo encontrado na pesquisa.
} 


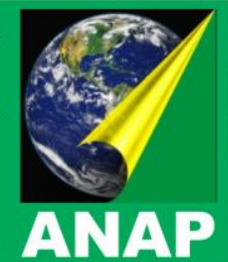

da Mota, 1998) ${ }^{4}$, afim de obter o valor de opção do recurso água no município de Meruoca/CE.

\subsection{DESENVOLVIMENTO}

As análises e discussões dos resultados, a seguir, traz aspecto sócio-econômicoambiental dos entrevistados procurando revelar um perfil de indivíduo disposto a pagar pelo recurso água em seu espaço geográfico. Correlacionando condições para disponibilizar, disposição a pagar e, por fim, agregar valor ao recurso natural em questão - a água.

$\mathrm{Na}$ tabela 1, percebe-se que dos 50 participantes entrevistados $68 \%$ é do sexo feminino, possuindo como média para faixa etária de idade 38 anos, onde mais de $60 \%$ dos mesmos são casados, $32 \%$ solteiros, $4 \%$ separados e $2 \%$ viúvo; em que $80 \%$ mora em área urbana do município de Meruoca/CE e apenas 20\% residem em área rural; possuindo dentre os pesquisados, uma média de 4 pessoas morando no domicílio.

Lê-se no gráfico 2 que, do total de participantes, 36\% possuem grau de escolaridade ensino médio completo/incompleto; $36 \%$ ensino fundamental completo/incompleto; apenas $28 \%$ ensino superior completo/incompleto.

Quanto maior o grau de escolaridade, subtende-se maior arcabouço de informações, modelando assim, costumes domésticos com relação à utilização da água, como a higiene pessoal; o manuseio de asseio das roupas, louças; além da própria manipulação para consumo oral através de líquidos e alimentos.

O gráfico 3 reporta informações relacionadas aos aspectos econômicos dos indivíduos, mostrando que:

1. Os beneficiários do governo são considerados aqueles indivíduos que recebem crédito do governo para acréscimo na renda domiciliar, afim de ajudar nos custos fixo do domicílio, por exemplo, bolsa escola ${ }^{5}$ e bolsa família ${ }^{6}$, os quais foram os

\footnotetext{
${ }^{4}$ DAPT $=\Sigma$ DAPMi (ni/N) (X)

$\mathrm{n}=1 \quad$ Em que DAPT (disposição a pagar total), DAPMi (disposição a pagar média), ni (número de entrevistados dispostos a pagar), N (Número total de pessoas entrevistadas), y (número de intervalos relativos às respostas quanto a DAP), i (um dos intervalos relativos às respostas quanto à DAP), X (população do município).

${ }^{5}$ Crédito dado pelo governo as crianças do domicilio, a fim de ajudar na educação do mesmo.
} 


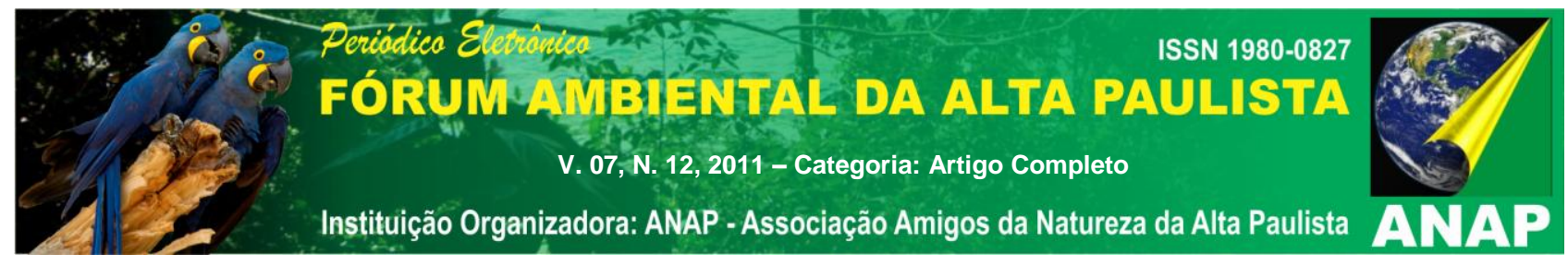

benefícios encontrados nesta pesquisa, cujo, 22\% são beneficiários (20\% sexo feminino e $2 \%$ masculino) e $78 \%$ não são beneficiários (48\% sexo feminino e $30 \%$ masculino).

2. Se trabalha atualmente: mais de $70 \%$ da população entrevistada possui algum tipo de trabalho ( $48 \%$ feminino e $28 \%$ masculino), dentre estes são: emprego temporário, permanente, autônomo; $16 \%$ são desempregados (12\% feminino e $4 \%$ masculino) e $8 \%$ somente do sexo feminino são aposentadas.

3. Quanto à carteira assinada: mostra que quase $80 \%$ trabalham sem carteira assinada, o que possui carteira assinada é representado por $10 \%$ dos entrevistados sendo $8 \%$ mulher e $2 \%$ homem e, outros $8 \%$ são as mulheres aposentadas.

Ainda neste momento da pesquisa pode-se constatar que a maioria destas pessoas que possuem algum tipo de ocupação, trabalha em área urbana, destinando sua renda ao sustento da família.

O Gráfico 4 mostra que $22 \%$ dos participantes ganham até ou igual a um salário mínimo por mês, $70 \%$ ganham entre dois a quatro salários mínimos mensais e $8 \%$ ganham igual ou acima de cinco salários mínimos ao mês. Revelando um percentual de renda razoável, podendo, posteriormente, dedicar uma porção da mesma a destinar para pagamento da água para sua utilização conforme suas necessidades.

O meio de comunicação é a fonte de informação do indivíduo, podendo torná-lo um ser capaz de discussões acerca de qualquer assunto. Porém nesta região, existe um precário veículo de comunicação, onde quase ninguém tem facilidade na acessibilidade destes. Apenas $36 \%$ da população ouve o noticiário através de rádio diariamente; somente $12 \%$ tem acesso a leitura de um jornal, enquanto $88 \%$ nunca chegou a ler um jornal ou raramente teve acesso ao mesmo; $96 \%$ dos entrevistados nunca tiveram acesso a revista ou se tiveram alguma oportunidade, foi raramente; sendo apenas $4 \%$ leitores de revista diariamente; quanto a internet, que exige de uma maior tecnologia para obter acesso, é relevante o que os entrevistados revelaram, em que $46 \%$ tem acesso a internet diariamente, porém não se pode incorporar a internet como um viável veículo de noticias porque depende dos conteúdos acessados pelos indivíduos; já a televisão, obtém-se um

\footnotetext{
${ }^{6}$ Crédito dado pelo governo as famílias de baixa renda, a fim de ajudar nos custos fixos do domicilio.
} 


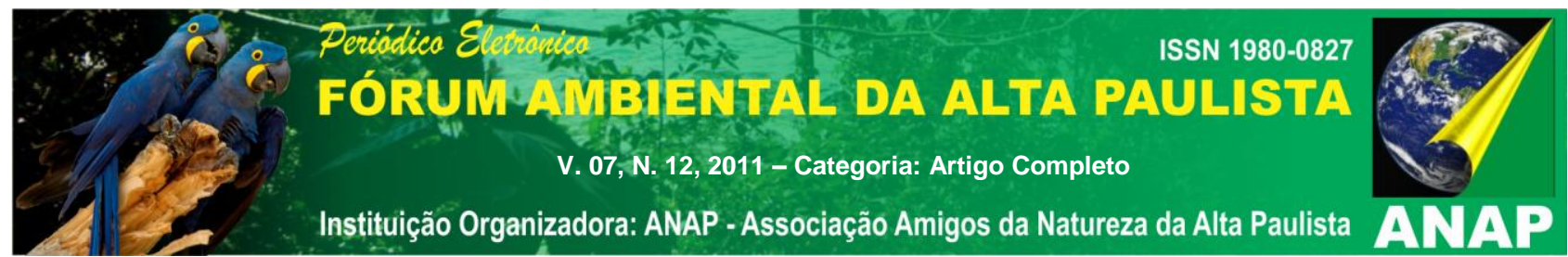

total de $80 \%$ de adesão, considerado um meio de comunicação universal, levando além de notícias globais (informativas, trágicas, descobertas, etc.) dá ao consumidor um certo poder critico quando envolvido com historias de novelas e mini-séries, o que não sendo via de regra, mas acaba adentrando em seu comportamento pessoal.

Segundo a pesquisa constata-se que $62 \%$ possuem captação de água através da rede geral da CAGECE que possuem instalações no município e, 32\% são abastecidos por água através de outros meios de captação como poço profundo, cacimba e rio. Dentre os participantes $98 \%$ utiliza esta água única e exclusivamente para consumo próprio na ingestão do próprio líquido na manipulação de alimentos para produção de comida, higiene e usos domésticos e, somente $2 \%$ além de utilizar a água para consumo próprio também a utiliza para trabalho em manejo de agricultura irrigada.

Ainda neste momento da pesquisa foi possível identificar através das preocupações demonstradas pelo entrevistado que no período do segundo semestre do ano, principalmente, os meses de setembro, outubro e novembro possuem muitas dificuldades de água, pois o abastecimento, já existente, sendo insuficiente, adere-se a captação através da natureza (poço, cacimba e rio) e, estes recursos, neste período ficam escassos, deixando-os com problemas de captação de água, o que é complicado, pois esta se falando de utilização da água para consumo próprio, ou seja, necessidades básicas.

De acordo com gráfico 6 verifica-se que 24\% dos entrevistados possuem pouca necessidade por água, 44\% razoável, 28\% muita e 4\% em abundância. Estes números mostram que a necessidade por água é relevante quanto ao seu uso e, tomando como observação maior, percebe-se que mais de $70 \%$ dos entrevistados têm necessidade de uma quantidade maior de água, pois sua alocação acontece de forma prioritária e, dependendo do espaço e da quantidade de pessoas no domicílio, sua utilização será mesmo de extrema necessidade e em grandes escalas.

O gráfico 7 faz uma relação da qualidade da água segundo o tipo abastecimento, ou seja, a captação de água de cada domicilio. Em termos de abastecimento via Cagece, $10 \%$ da população entrevistada dizem que possui qualidade boa, $26 \%$ têm qualidade razoável, $20 \%$ ruim e $6 \%$ muito ruim; quanto aos outros tipos de captação de água como 


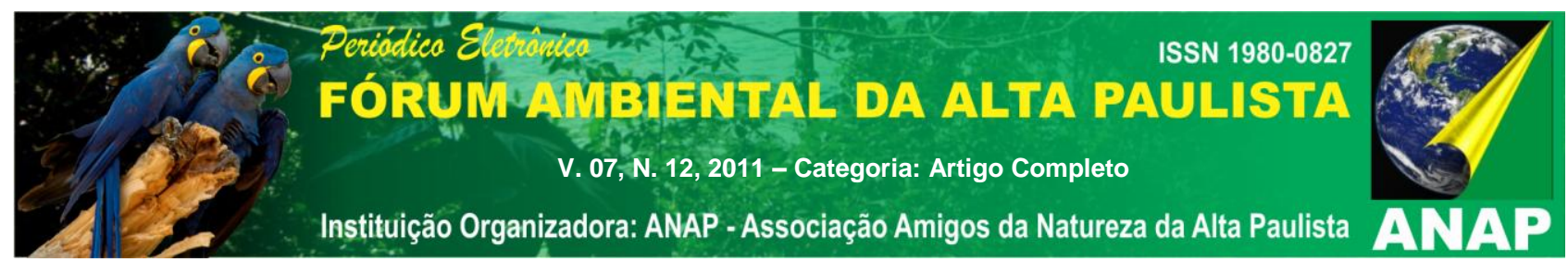

mencionados pelos participantes ao longo do estudo como poço, cacimba, rio $24 \%$ a caracterizam como boa, $8 \%$ razoável, $4 \%$ ruim e $2 \%$ muito ruim.

Lembrando que água potável é um direito do individuo ${ }^{7}$ seja ela qual for à forma de captação, porém identifica-se nestes resultados que por mais que exista uma rede geral de abastecimento no município e esta, abrangem mais de $60 \%$ da população entrevistada, a qualidade da água das outras fontes, que são ditas 'naturais' é melhor que a água que provem da rede geral.

A tabela 3 mostra que mais de 1/3 da população entrevistada possuem dificuldade de abastecimento de água. Há relatos dos próprios entrevistados que a rede geral que possuem como abastecimento principal é muito instável, pois seu funcionamento ao dia é de apenas doze horas e, neste momento, a população tem que fazer reservas do máximo de água possível em reservatório para suprir suas necessidades no restante das outras 12 horas do dia, caso contrário, ficam sem água, aqueles que não possuem outra forma de captação, revelam ainda que existem problemas na manutenção das instalações da rede geral, pois há uma freqüência grande de defeitos na parte hidráulica que deixa a população sem água por ate 3 ou 4 dias seguidos.

Os que não possuem dificuldade de água, relata que, além da rede geral, possuem também outras formas de captação de água como poço, cacimba e rio, que mesmo assim ainda revelam problemas quanto a escassez dos recursos no período do segundo semestre do ano, quando o período chuvoso acaba e tende de se usar dos recursos em reserva natural, que ao longo dos meses do período de seca vão se exaurindo.

Percebe-se ainda nos resultados descritos na tabela 3 que $84 \%$ da água consumida pelos indivíduos em estudo é filtrada e que 16\% não é filtrada, e que em torno de $18 \%$ relatam terem crianças no domicilio que tiverem diarréia, o que indica que a água

\footnotetext{
${ }^{7}$ Declaração Universal dos Direitos da Água, Art. 2o - A água é a seiva do nosso planeta.Ela é a condição essencial de vida de todo ser vegetal, animal ou humano. Sem ela não poderíamos conceber como são a atmosfera, o clima, a vegetação, a cultura ou a agricultura (www.suapesquisa.com/datascomemorativas/dia_mundial_da_agua.htm). O direito à água é um dos direitos

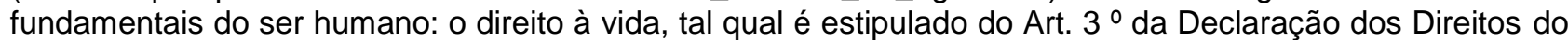
Homem - Todo 0 indivíduo tem direito a vida, liberdade $e$ à segurança (www.cnpcjr.pt/preview_documentos.asp?r=1458\&m=PDF)
} 


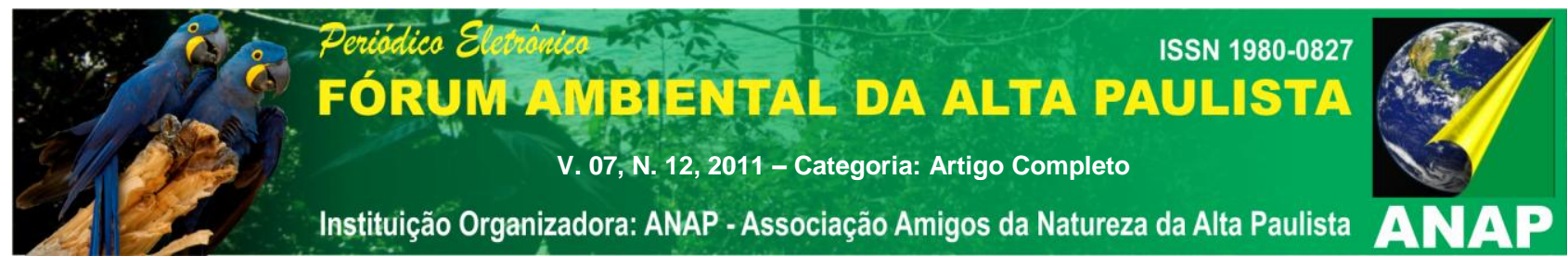

ingerida por estas crianças não é de boa qualidade admitindo um estado de saúde amenos

\subsubsection{Estimativas ao Recurso Água Segundo a fórmula matemática}

Segundo a Organização Mundial de Saúde - OMS (BRASIL, 2004) um dos parâmetros de suspeita da causa para o aparecimento de diarréia em crianças é a má qualidade da água ingerida pelas mesmas.

Quanto aos aspectos relacionados à DAP, expostos no gráfico 8 , admitindo que 96\% da população amostral têm condição de pagar para ter água e, estes dado esta diretamente ligado a renda do domicílio, pois como revelado na figura $3-100 \%$ dos participantes possuem alguma renda, sendo rendas, entre intervalos de até 1 salário mínimo e acima de cinco salários; ainda no gráfico acima $80 \%$ destes estão dispostos a pagar para ter água conforme sua necessidade diária, $86 \%$ acredita que se existisse uma forma de captação de água através de uma rede geral que seja suficiente e sem problemas aparentes, o qual, a população total do município estaria disposta a pagar por este recurso e, que no período do estudo entre setembro de 2010 a maio de $2011,58 \%$ dos estudados pagaram algum valor para terem água, chegando a uma média de $R \$$ 23,48 (vinte e três reais e quarenta e oito centavos) por mês.

O cenário hipotetizado para formar o arcabouço de estudo sobre o método de valoração contingente, de acordo com Seroa da Motta (1998) seja de tal forma que as preferências reveladas nas pesquisas reflitam decisões que os agentes tomariam de fato, caso existisse um mercado para o bem ambiental descrito no cenário hipotético.

As técnicas de valoração buscam extrair a disposição individual a pagar por uma mudança no nível de oferta de um bem ambiental ou de um conjunto de tais bens e serviços. As abordagens podem envolver a valoração de bens e serviços individuais com subsequente agregação dos valores, ou a valoração de uma mudança no nível da oferta total do ecossistema. Em ambas as abordagens o que está sendo valorado é uma variação (incremento ou decréscimo) na oferta ou disponibilidade desses recursos (SCBD, 2001). 


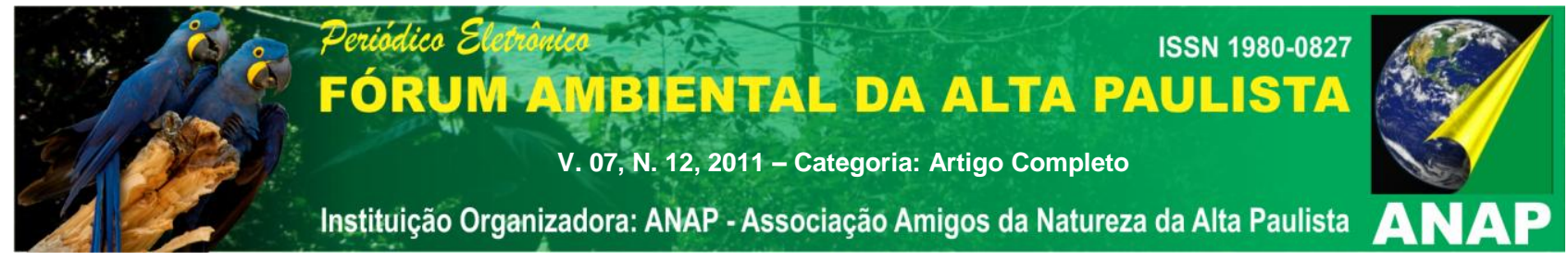

O uso residencial da água é o mais próximo ao de um bem privado, no sentido que os benefícios são altamente excludentes e rivais ${ }^{8}$. Mesmo quando os serviços de água são fornecidos por serviços públicos monopolísticos sob regulamentação, os consumidores relevarão uma demanda pelo serviço por determinada tarifa de água ou preço regulamentado. Esta demanda, por sua vez, refletirá a disposição dos consumidores a pagar.

Como foi colocado na metodologia deste trabalho, que para se encontrar um valor a um recurso natural, temos que utilizar dos meios do questionário criando cenários hipotéticos para determinadas situações em que a população possa vir a vivenciar.

Portanto, o que se pode analisar para cada situação é que no cenário $A, 26 \%$ da população não estão dispostos a pagar para ter água nesta situação e outras $74 \%$ pagariam algum valor entre $R \$ 0,01$ a 100,00 reais pra ter água; dentre as pessoas que deram alguma capacidade de pagamento ao recurso tivemos uma DAP igual a $R \$ 605,00$ (seiscentos e cinco reais), uma DAPM de $\mathrm{R} \$ 16,35$ (dezesseis reais e trinta e cinco centavos) ao mês - valor médio e mínimo em que os indivíduos estariam dispostos a pagar; e aplicando a fórmula sugerida por Eutrirak e Grandstaff, estimou-se um valor ao recurso água equivalente a $R \$ 153.670,00$ (cento e cinqüenta e três mil e seiscentos e setenta reias) ao mês.

$\mathrm{Na}$ situação descrita pelo cenário $\mathrm{B}$, temos que mais de $50 \%$ da amostra não estaria disposta a pagar para ter água, isso ocorre devido não optar por pagar por uma rede de abastecimento falho, porém outros $48 \%$ estão dispostos a pagar para ter água mesmo que seja uma forma de abastecimento insuficiente do que não pagar e não possuir água nenhuma para atender as suas necessidades diárias.

Devido ao grande numero de pessoas não dispostas a pagar pelo recurso, o DAP diminui chegando a $R \$ 316,00$ (trezentos e dezesseis e seis reais) assim como o DAPM, chegando a um valor médio e mínimo de $R \$ 13,17$ (treze reais e dezessete centavos) ao mês. Em conseqüência, o valor estimado ao recurso água como um todo no município de

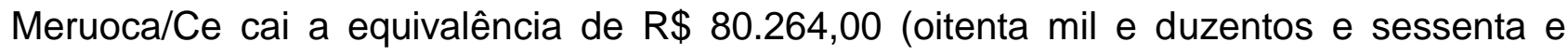
quatro reais) ao mês.

\footnotetext{
${ }^{8}$ Excludentes e rivais - Um Bem é dito Excludente se sua utilização pode ser impedida e um Bem é considerado Rival quando ele não pode ser usado (consumido) por muitas pessoas simultaneamente.
} 


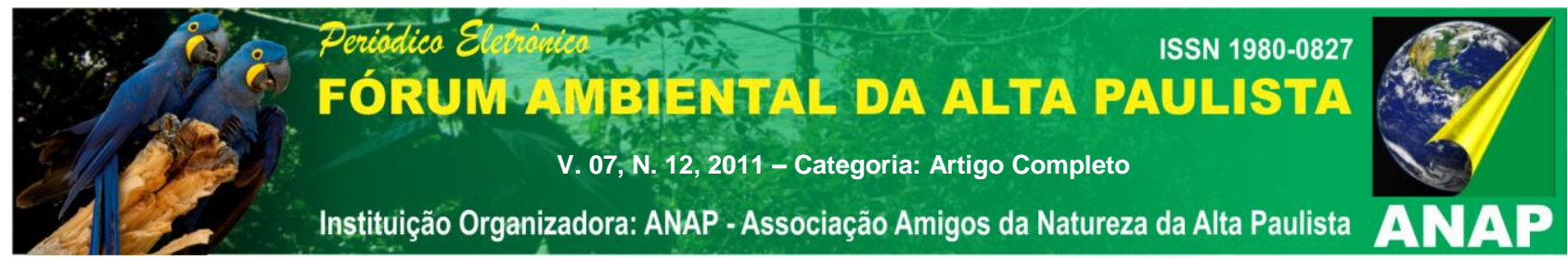

No terceiro e último cenário C, $46 \%$ da população participante não estão dispostas a pagar valor nenhum pelo recurso, onde outras $54 \%$ estão dispostas a pagar algum valor entre os estratos sugeridos na tabela acima.

Percebe-se que destes $64 \%$, existem $2 \%$ que valorizam bastante as outras formas de abastecimento que não seja a rede geral, pois estão dispostas à pagar valores entre $R \$ 50,01$ - 100,00 reais, devido a este estrato percebe-se um aumento no DAP sendo de $R \$ 422,00$ (quatrocentos e vinte e dois reais), um valor de DAPM médio e mínimo de $R \$$ 15,63 (quinze reais e sessenta e três centavos) ao mês, porém devido ainda a alta quantidade de pessoas que não estão dispostas a pagar e 2 pessoas valorando o recurso bem mais que os outros participantes, o valor estimado para o recurso equivale a $R \$$ 107.188,00 (Cento e sete mil e cento e oitenta e oito reais) ao mês, mostrando o valor agregado dado ao recurso água neste cenário é relevante quando trata-se de recursos 'naturais' mesmo considerando sua escassez em algum período do ano.

\subsection{CONCLUSÃO}

O presente estudo possui em suas características sócio-econômicas-ambientais resultados significativos e, por vezes bastante correlacionados em que $68 \%$ dos entrevistados é do sexo feminino; dos entrevistados $80 \%$ residem na área urbana possuindo $36 \%$ de escolaridade em torno do ensino médio, provando um certo grau de informação acerca de questões globais como o meio ambiente, utilizam-se como maior veiculo de comunicação a televisão e como segundo a internet, apesar de não incluir como grande fonte de informação porque depende dos conteúdos de acesso feito por cada individuo. Dos participantes, mais de $60 \%$ trabalham e outros $16 \%$ são aposentados, porém os resultados relacionados a renda mostra que $100 \%$ possuem alguma renda no domicilio, apesar de nem todos os entrevistados trabalharem, existe pelo menos um individuo na residência que trabalha, levando a família possuir alguma renda, esta que é gasta no sustento da família.

Quanto à disponibilidade de água, $100 \%$ têm acesso à água, destes $56 \%$ é abastecimento através da rede geral da Cagece e outros $62 \%$ abastecidos de outras fontes como poço, cacimba e rio, $98 \%$ utiliza-a para consumo próprio em suas necessidades diárias, que em geral não é considerada de boa qualidade, há ainda, 38\% 


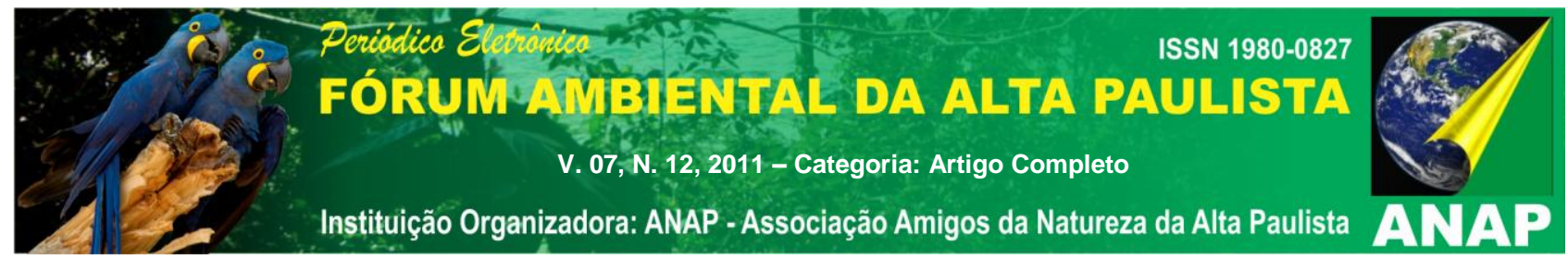

da população amostral com dificuldade de água, ora por questões de má manutenção nas instalações da rede geral, ora por questões de precipitações que promove a escassez do recurso nas fontes naturais.

Segundo os resultados encontrados neste estudo necessitou-se de criar um valor ao recurso natural água, afim de definirmos em que condições esta população estaria disposta a pagar para uso do recurso sem restrições. Utilizando-se da formula sugerida por Eutrirak \& Grandstaff apud Seroa da Mota (1998), encontrou-se uma maneira, segundo os cenários hipotéticos criados, de atribuirmos uma disposição média a pagar (DAPM) ao mês que fosse um valor mínimo, perante os DAP's dos respondentes e também estimar um valor agregado ao recurso natural água (DAPT) no município de Meruoca-Ce. Nestes, os resultados mostram que quanto maior o numero de pessoas dispostas a pagar, maior será o valor agregado ao recurso natural água (DAPT), como revela o cenário $A$, possuindo uma DAPM correspondente aos valores atribuídos aos DAP's sugeridos pelos entrevistados; já no cenário $B$ revela-se uma diminuição no valor agregado (DAPT) devido ao alto índice de pessoas que não estão dispostas a pagar, provando o não-valor que atribuem ao recurso é observado na diminuição do DAPM e na redução no valor de DAP's sugeridos, porém isso aconteceu porque dado o cenário hipotético, as pessoas não querem pagar por um sistema de abastecimento falho; no terceiro cenário $\mathrm{C}$, observa-se uma pequena desvalorização no valor agregado do recurso (DAPT) em relação ao cenário $\mathrm{A}$ e um alto valor agregado quanto ao $\mathrm{B}$, o valor agregado dado à água no cenário $C$ é bem importante porque por mais que não tenha sido o maior valor encontrado entre as situações sugeridas, requer observar que $R \$ 107.188,00$ (cento e sete mil e cento e oitenta e oito reais) atribuído ao recurso baseado num abastecimento dito 'natural' através de poços, cacimbas e rios, é interessante, isso porque, em resultados outrora esclarecidos, observou-se uma maior qualidade na água proveniente desta forma de abastecimento do que através do abastecimento da rede geral.

\section{NUMERAÇÃO PROGRESSIVA}

\section{Indicativo}

Numérico

Apresentação 


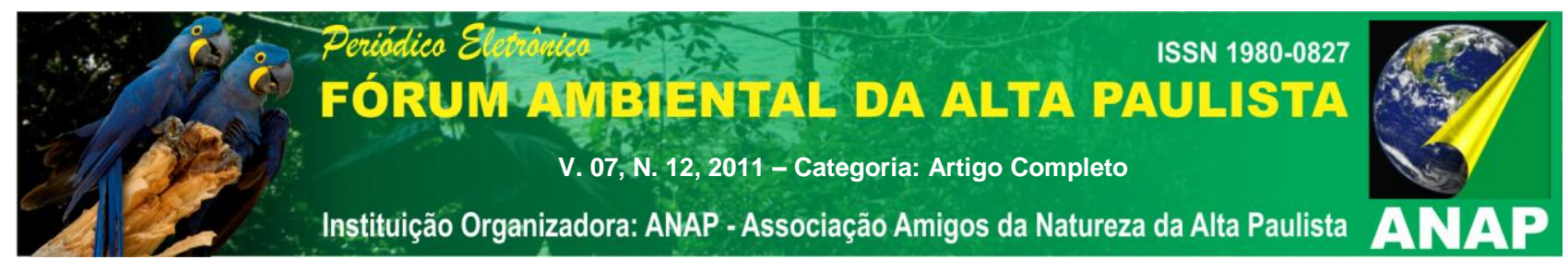

\section{ESTRUTURA}

1.1 INTRODUÇÃO

1.2 DESENVOLVIMENTO

1.2.1 Estimativas ao Recurso Água segundo a Fórmula Matemática

1.3 CONCLUSÃO

2 NUMERAÇÃO PROGRESSIVA

3 ILUSTRAÇÕES

3.1 TABELAS

4 REFERÊNCIAS BIBLIOGRÁFICAS

\section{ILUSTRAÇÕES}

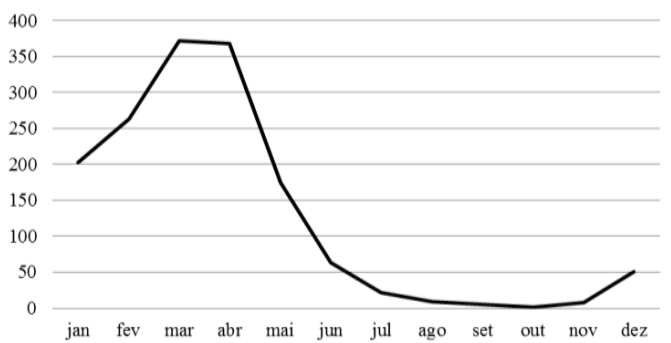

\section{GRÁFICO 1 - PRECIPITAÇÃO MÉDIA MENSAL}

FONTE: FUNCEME
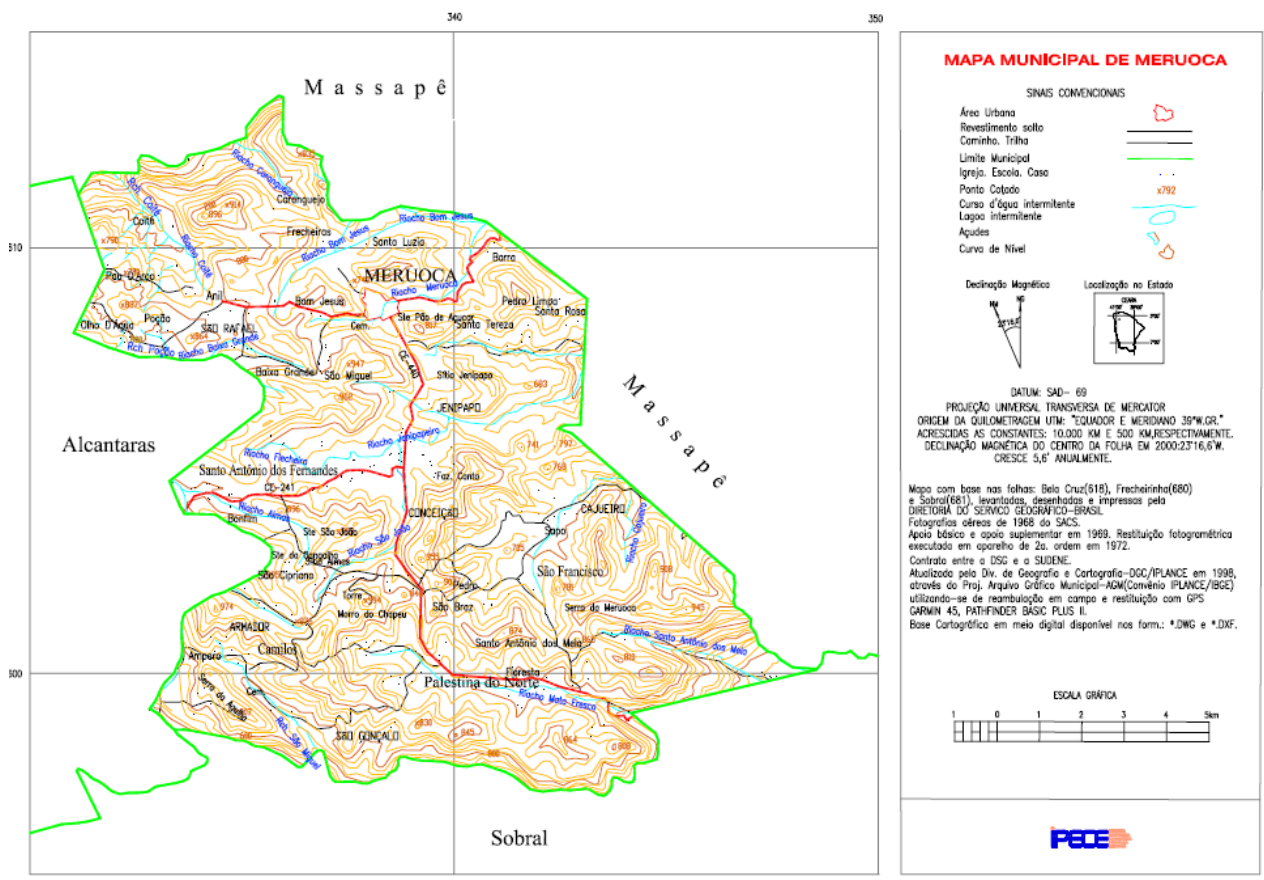


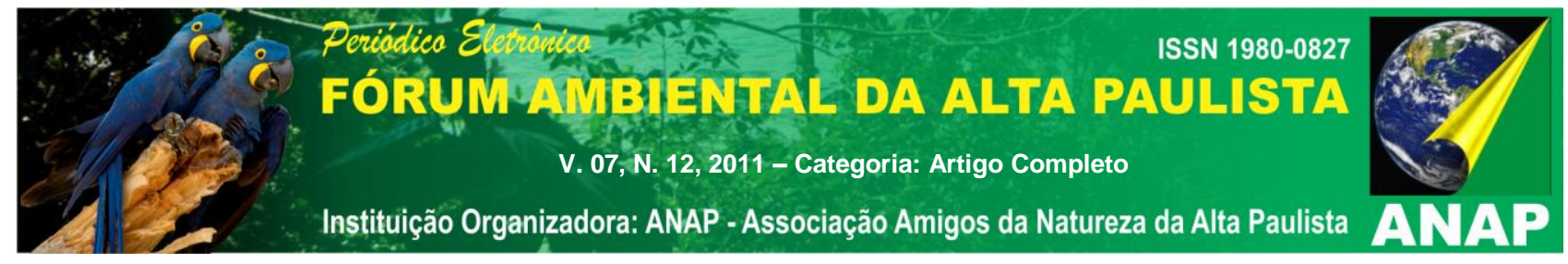

FIGURA 1 - MAPA MUNICIPAL DE MERUOCA

FONTE: IPECE (2010)

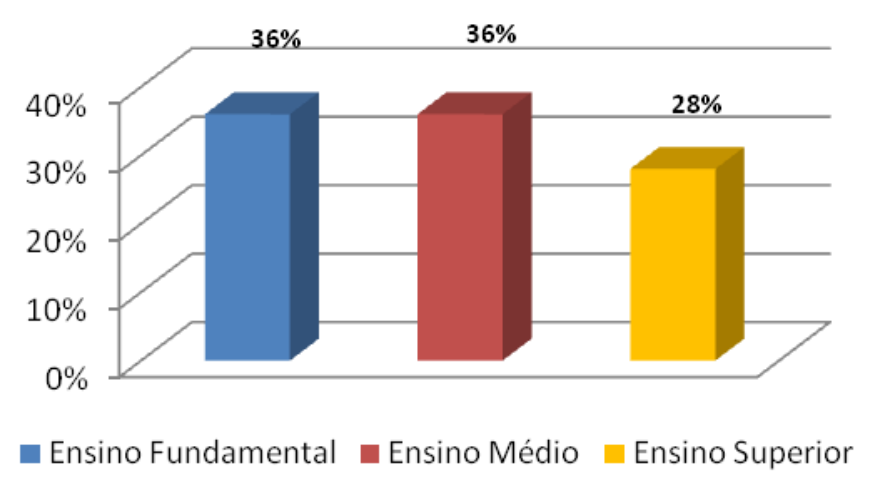

GRÁFICO 2 - Escolaridade dos Entrevistados

FONTE: Elaborada pela autora

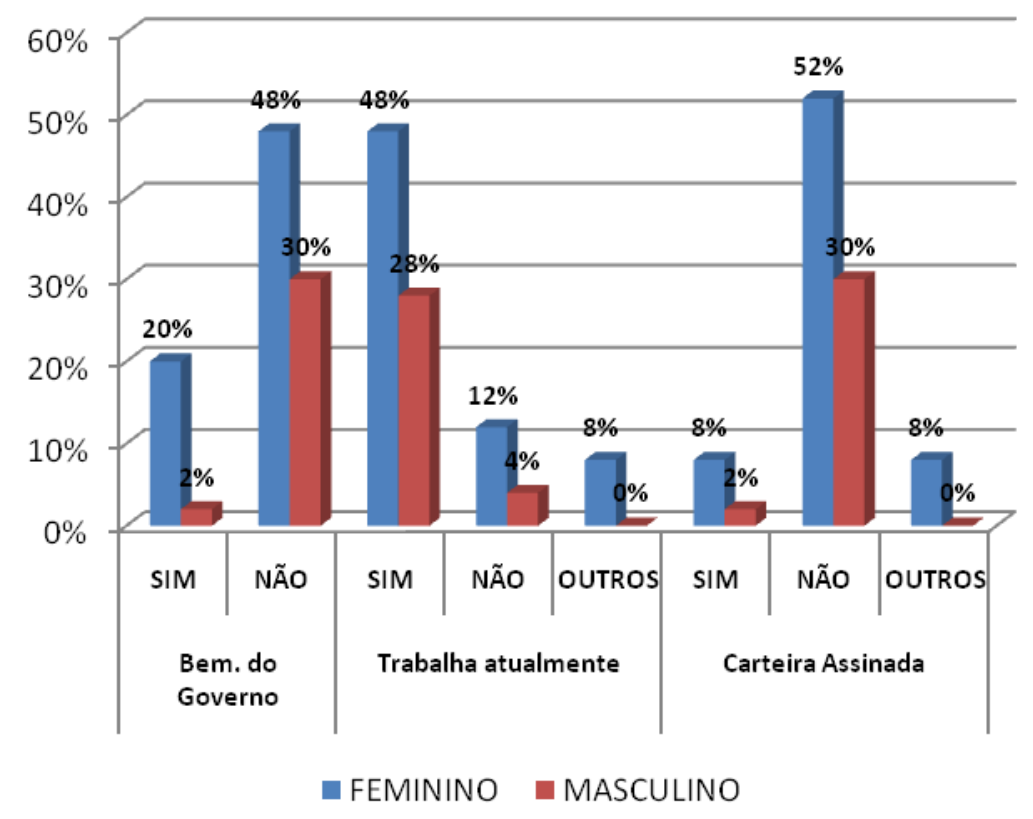

GRÁFICO 3 - Características Econômicas dos Entrevistados

FONTE: Elaborada pela autora 

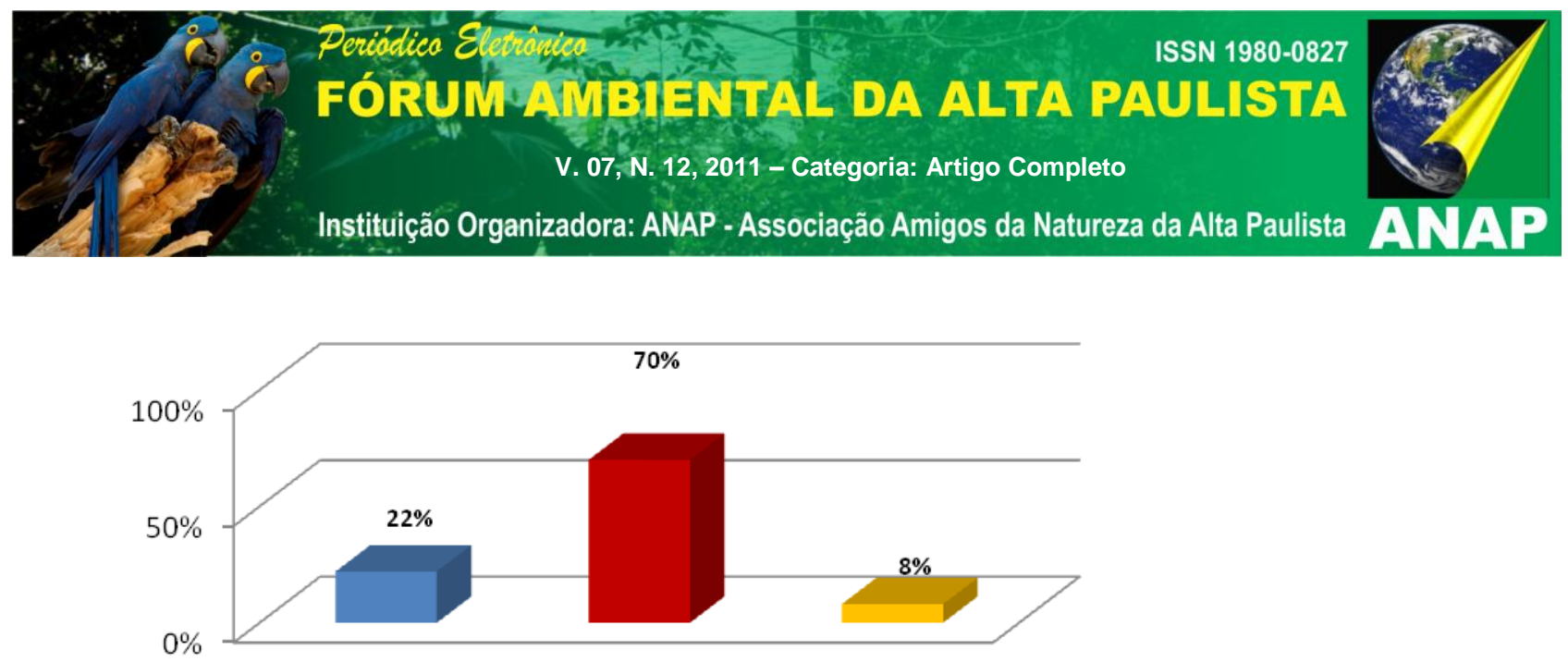

- Até 1 Salário Mínimo De 2 a 4 Salários Mínimo Acima de 5 Salários Mínimo

\section{GRÁFICO 4 - Renda Mensal do Domicílio dos entrevistados}

FONTE: Elaborada pela autora

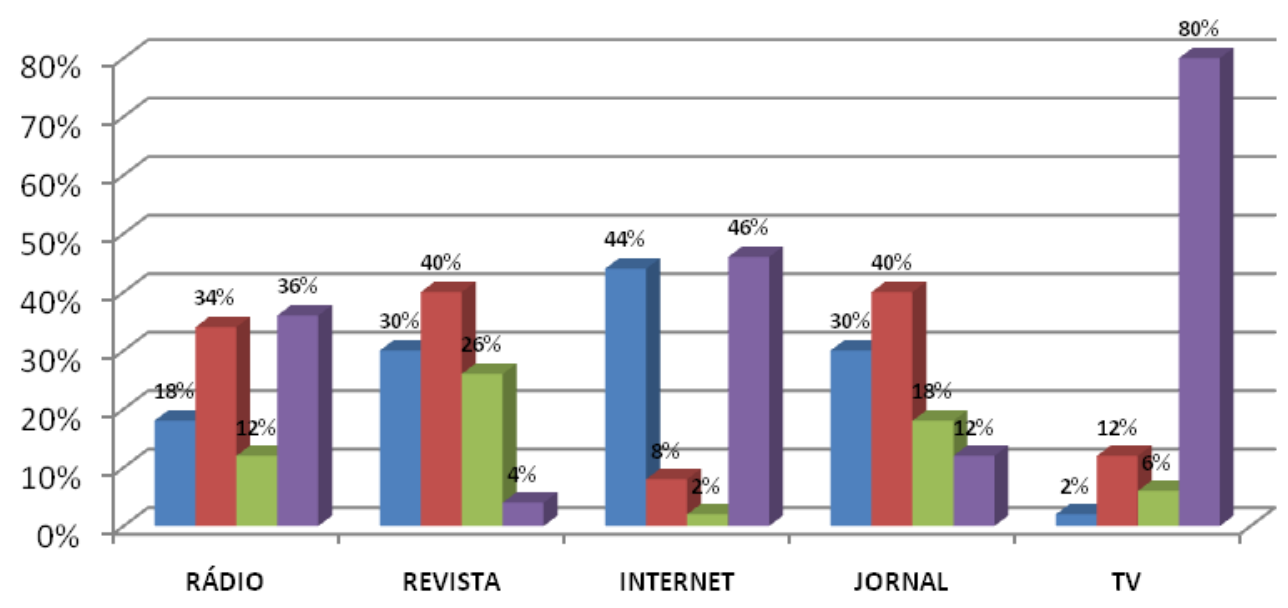

NUNCA $\square$ SIM, RARAMENTE $\square$ SIM, UMA VEZ POR SEMANA $\square$ SIM, DIARIAMENTE

\section{GRÁFICO 5 - Meios de comunicação utilizados pelos entrevistados}

FONTE: Elaborada pela autora

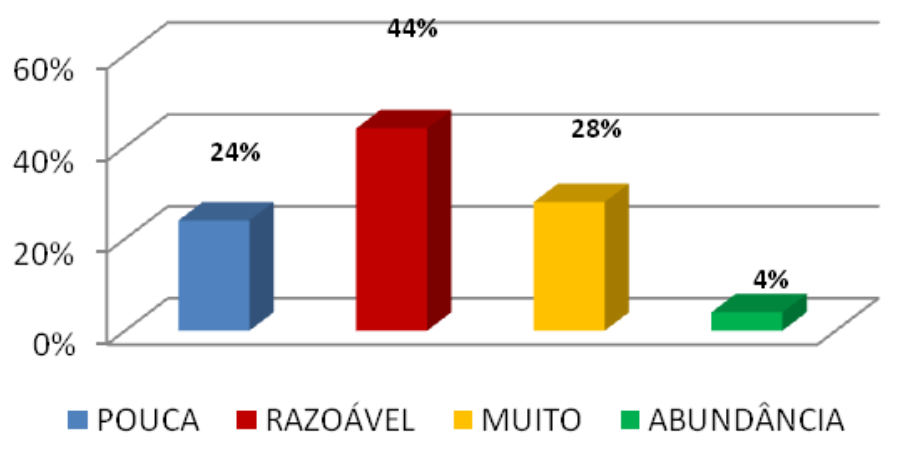

GRÁFICO 6 - Necessidade que os entrevistados possuem quanto a água FONTE: Elaborada pela autora 

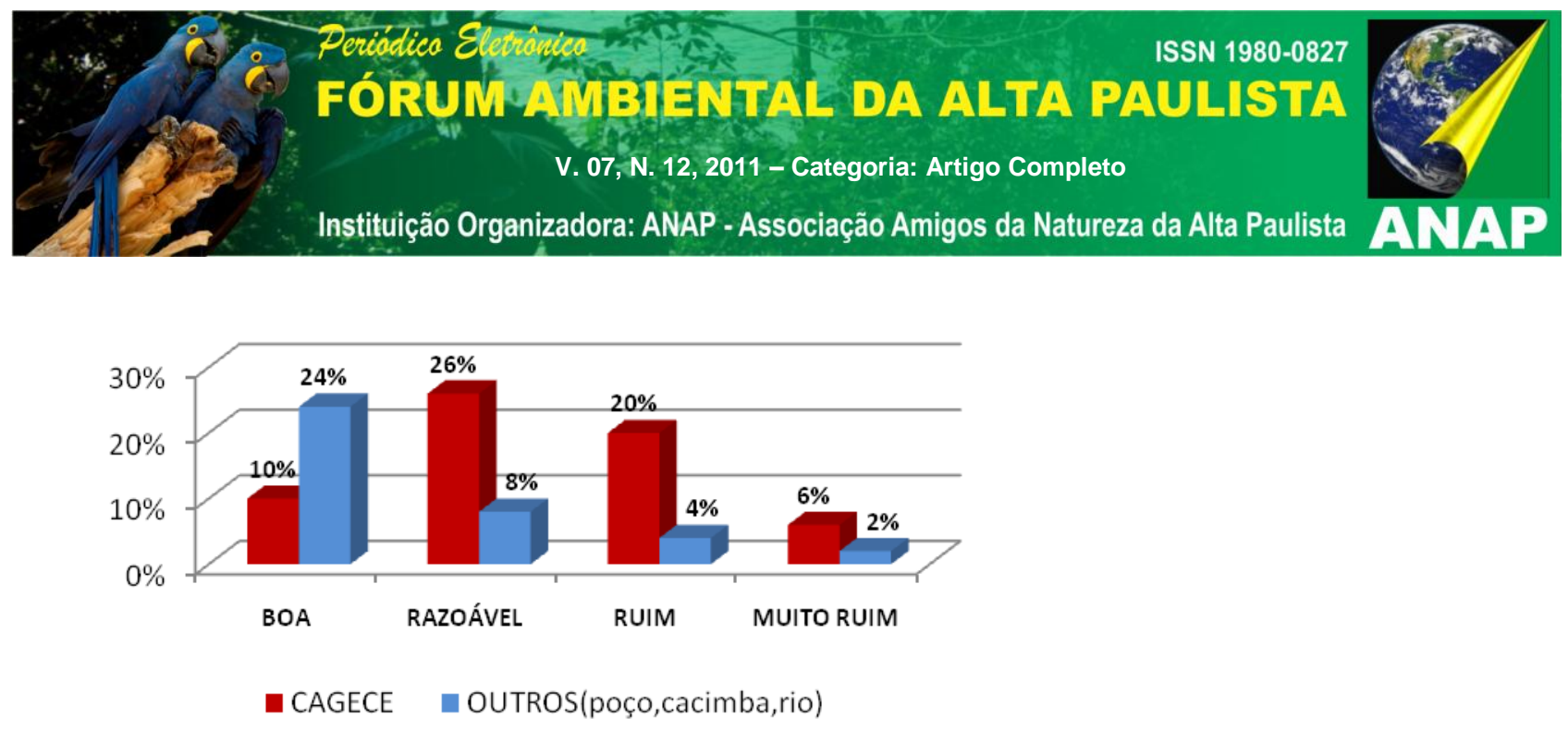

GRÁFICO 7 - Qualidade da água x Forma de abastecimento relatada pelos entrevistados FONTE: Elaborada pela autora

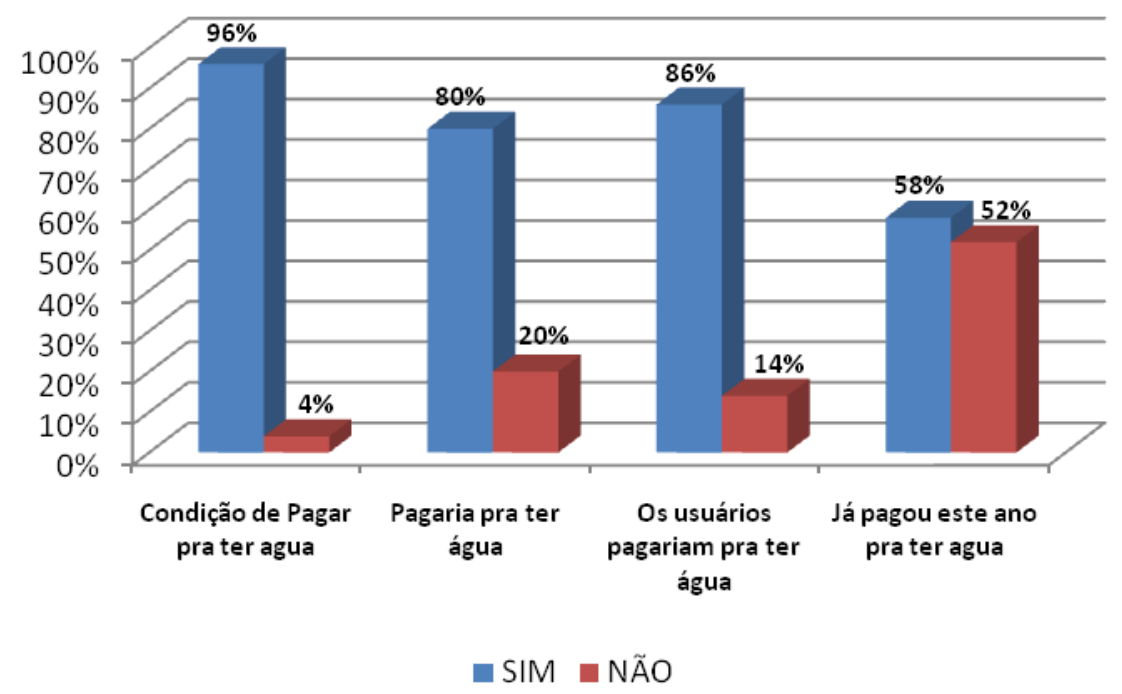

GRÁFICO 8 - Aspectos relativos ao DAP dos entrevistados

FONTE: Elaborada pela autora

\subsection{TABELAS}

TABELA 1 - Perfil dos Entrevistados

\begin{tabular}{l|ll}
\hline SEXO (\%) & Feminino & 68 \\
\hline FAIXA ETÁRIA & Masculino & 32 \\
\hline
\end{tabular}




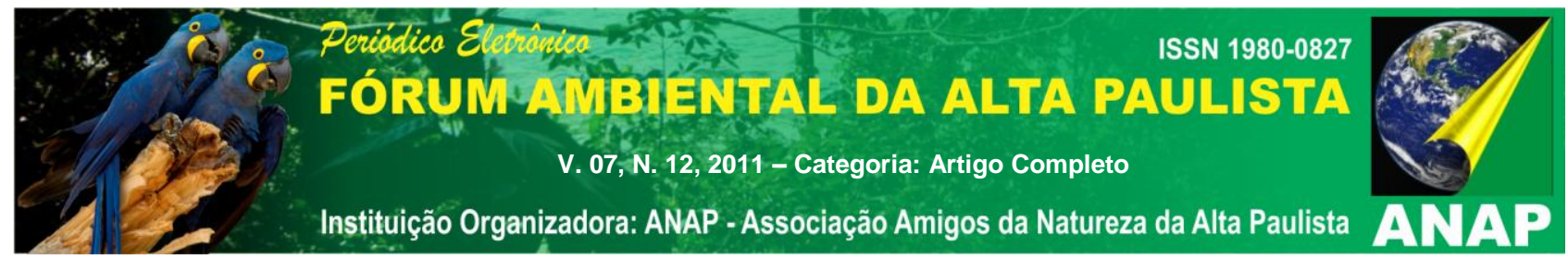

\begin{tabular}{l|lr}
\hline ESTADO & Casado & 62 \\
CONJUGAL (\%) & Solteiro & 32 \\
& Separado & 4 \\
& Viúvo & 2 \\
\hline SITUAÇÁO & Rural & 20 \\
CENSITÁRIA (\%) & Urbano & 80 \\
\hline No DE PESSOAS & 4 \\
NO DOMICÍlLIO &
\end{tabular}

FONTE: Elaborada pela autora

TABELA 2 - Acesso a água dos entrevistados

\begin{tabular}{l|lr}
\hline \multirow{2}{*}{ CAPTAÇÃO DA ÁGUA (\%) } & CAGECE & 62 \\
& Outros( poço, & 32 \\
& cacimba,rio)
\end{tabular}

FONTE: Elaborada pela autora

TABELA 3 - Relatos dos entrevistados sobre a água

\begin{tabular}{ccc}
\cline { 2 - 3 } & SIM (\%) & NÃO (\%) \\
\hline DIFICULDADE DE ÁGUA & 38 & 62 \\
\hline $\begin{array}{c}\text { ÁGUA PARA BEBER É } \\
\text { FILTRADA? }\end{array}$ & 84 & 16 \\
\hline $\begin{array}{c}\text { APARECIMENTO DE } \\
\text { CRIANÇA COM } \\
\text { DIARRÉIA }\end{array}$ & 18 & 82 \\
\hline FIANTE: & &
\end{tabular}

FONTE: Elaborada pela autora

TABELA 4 - Estimativa segundo o valor de opção

\begin{tabular}{|c|c|c|c|c|c|c|c|c|}
\hline \multicolumn{9}{|c|}{ ESTIMATIVA DE DAP SEGUNDO O VALOR DE OPÇÃO } \\
\hline \multicolumn{9}{|l|}{ CENÁRIO A } \\
\hline intervalo(R\$/mês) & média(DAP/ni) (r\$) & pessoas (ni) & $\%(\mathrm{ni} / \mathrm{N})$ & População total & $\mathrm{ni} / \mathrm{N}$ & DAPT (r\$) & DAPM $^{*}(r \$)$ & $\mathrm{DAP}^{* *}(\mathrm{r} \$)$ \\
\hline $\begin{array}{r}0,00 \\
0,01-5,00 \\
5,01-25,00 \\
25,01-50,00 \\
50,01-100,00\end{array}$ & $\begin{array}{r}0,00 \\
3,00 \\
15,36 \\
40,00 \\
0,00\end{array}$ & $\begin{array}{r}13 \\
5 \\
28 \\
4 \\
0\end{array}$ & $\begin{array}{r}26 \\
10 \\
56 \\
8 \\
0\end{array}$ & & $\begin{array}{r}0,26 \\
0,1 \\
0,56 \\
0,08 \\
0\end{array}$ & $\begin{array}{r}3810 \\
109220 \\
40640 \\
0\end{array}$ & & \\
\hline TOTAL & & 50 & 100 & 12700 & & 153670,00 & 16,35 & 605,00 \\
\hline intervalo(R\$/mês) & média(DAP/ni) (r\$) & pessoas (ni) & $\%(\mathrm{ni} / \mathrm{N})$ & População total & ni/N & DAPT (r\$) & $\mathrm{DAPM}^{*}(\mathrm{r} \$)$ & $\mathrm{DAP}^{* *}(\mathrm{r} \$)$ \\
\hline 0,00 & 0,00 & 26 & 52 & & 0,52 & & & \\
\hline $0,01-5,00$ & 4,00 & 5 & 10 & & 0,1 & 5080 & & \\
\hline $5,01-25,00$ & 13,67 & 18 & 36 & & 0,36 & 62484 & & \\
\hline $25,01-50,00$ & 50,00 & 1 & 2 & & 0,02 & 12700 & & \\
\hline $50,01-100,00$ & 0,00 & 0 & 0 & & 0 & 0 & & \\
\hline TOTAL & & 50 & 100 & 12700 & & 80264,00 & 13,17 & 316,00 \\
\hline
\end{tabular}




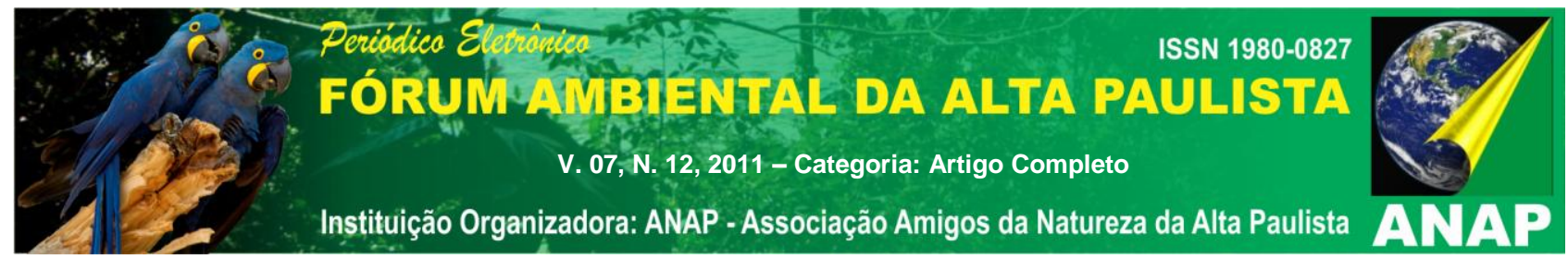

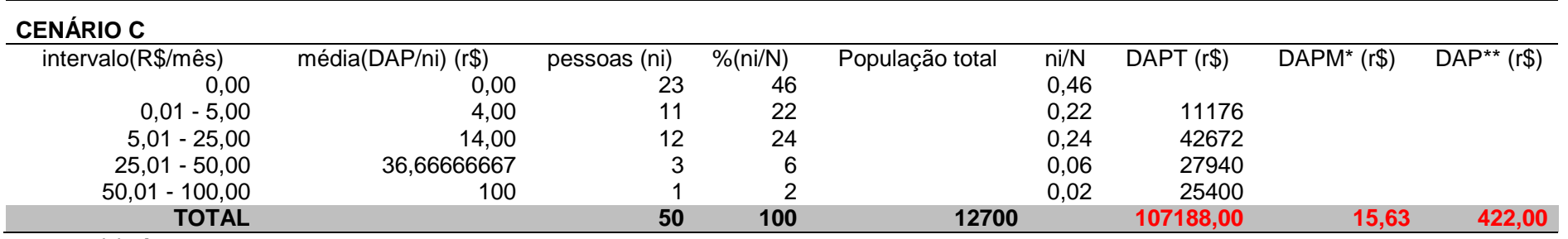

$\left({ }^{*}\right)$ é a soma de todos os valores relatado pelos entrevistados disposto a pagar pelo recurso dividido pelo numero de entrevistados

$\left({ }^{* *}\right)$ é a soma de todos os valores relatado pelos entrevistados disposto a pagar pelo recurso

FONTE: Elaborada pela autora

\section{REFERÊNCIAS BIBLIOGRÁFICAS}

BRASIL (2004). Qualidade da Água para Consumo Humano e seu Padrão de

Potabilidade. Disponível em: http://www.agua.bio.br/botao e S.htm Acesso em:

18.04.2011

Declaração Universal dos Direitos das Águas. Disponível em:

http://www.suapesquisa.com/datascomemorativas/dia mundial da agua.htm. Acesso em:

23 de junho de 2011.

Declaração Universal dos Direitos dos Homens. Disponível em:

http://www.cnpcir.pt/preview documentos.asp? $r=1458 \& \mathrm{~m}=P D F$. Acesso em: 23 de junho de 2011.

INSTITUTO BRASILEIRO DE GEOGRÁFIA E ESTATÍSTICA (IBGE). Produto Interno Bruto dos municípios. $2002-2005$.

INSTITUTO BRASILEIRO DE GEOGRÁFIA E ESTATÍSTICA (IBGE). Estimativas da População. 2009.

MAY, Peter H.; LUSTOSA, Maria Cecília; VINHA DA Valéria. Economia do Meio Ambiente: teoria e prática. Rio de Janeiro: Elsevier, 2003. 6ํㅗ impressão.

PNUD. Atlas do Desenvolvimento Humano: ranking decrescentes do IDH-M dos municípios do Brasil. 2000.

POLIT, D. F.; HUNGLER, B. P. Fundamentos da Pesquisa. 3 ed. Porto Alegre: Artes Médicas, 1995.

SCBD (Secretariat of the Convention on Biological Diversity). The value of forest ecosystems. Montreal: SCBD, 2001. 67p. (CBD Technical Series, 4).

SEROA DA MOTTA, R. Manual de Valoração Econômica do Meio Ambiente, Instituto Brasileiro de Meio Ambiente e Recursos Naturais Renováveis - IBAMA, 1998, no prelo. 